\title{
An Analysis of Vivie in Mrs. Warren's Profession Using Narrative Theory
}

\author{
Lin Bai \\ Shanxi Normal University, Linfen, China \\ Jie Qin \\ School of Foreign Languages, Shanxi Normal University, Linfen, China
}

\begin{abstract}
Bernard Shaw (1856-1950) is one of the world famous playwrights, is a household wordsmith for his good humor and satire. In his masterpiece Mrs. Warren's Profession, Shaw depicts a literary figure Vivie who embodies new women's yearning for their independence and aspirations of self-values. This paper analyzes Vivie's image through approaches of narrative theory. By using narrative voice reflected in the scene, involvement of implied author in portrayal description, application of feminism in narratology, and dualistic construction in subtext, readers can have a more profound understanding of Vivie's image. Instead of a mouthpiece of "new women", the nature of Vivie's image is just sketched out on the basis of an ideal man under the male-dominated capitalist society. This paper concludes that in the capitalist society women were under the control of patriarchal discourse.
\end{abstract}

Index Terms - Vivie, narrative theory, narrative voice, implied author, subtext, patriarchal discourse

\section{INTRODUCTION}

\section{A. Theoretical Significance and Practical Significance}

The critics generally believe that in Bernard Shaw's masterpiece Mrs. Warren's Profession, Mrs. Warren's daughter Vivie embodies new women's yearning for independence and aspirations of their social values during the period of Victorian age. In fact, only through the analysis of the narrative methods in Mrs. Warren's Profession can we help readers to deepen their understandings of Vivie's image. Studies have found that the essence of Vivie's image is just an ideal male model under the patriarchal discourse system rather than a new female's spokesperson. Modeled on the male image, Vivie's image still reflects that the patriarchal discourse controls women.

This paper will deeply analyzes the root of double oppression--character repression and economic oppression, suffered greatly by women. It is through analyzing the capitalist mode of production and its greedy nature of pursuing the maximized interests, we can explore Shaw's insights into the oppression and discrimination undergone by women as well as the problem of prostitution; and use this as a trigger to explore the initial views of feminism showed in Shaw's plays.

\section{B. Current Researches}

Narrative theory has now become an important perspective in the use of analyzing literary works. Narrative theory is originated in the west, and is famous for its formal criticism. In recent years, with the advance of globalization, it has become one of the vibrant and popular academic thoughts all over the world. Aristotle's Poetics is the earliest narrative work. In the eighteenth century discussions of narrative methods (especially in the novels) reached a more adequate and comprehensive stage: from the content of the novel to the form of the novel, and then to the novels' function and the position of readers, etc. In recent years, studies of narratology bring about not just the rapid increase of its research results, and more importantly, it is greatly expanded in the depth and breadth, from the classical narratology which focused on discourse to multivariate narratology in the early 1990s. Today, people become keen to discuss some of the narrative categories, such as the viewpoint, sound and distance involved in narrative theory.

\section{Structure of the Thesis}

This paper is divided into five parts:

The first part is the introduction, introducing theoretical and practical significance, current researches and structure of this paper.

The second part is literature review, including introduction to the author and introduction to the novel.

The third part is narrative theory, consisting of general introduction, background and three research types of classical narratology, and basic characteristics of post classical narratology.

The fourth part is a detailed analysis of Vivie from the perspective of narrative theory, involving narrative voice reflected in the scene, involvement of implied author in portrayal description, application of feminism in narratology, and dualistic construction in subtext. 
The fifth part is the conclusion. By analyzing Vivie's image, it can be safely concluded that the social root of this phenomena lies in the exploitative nature of the capitalist production mode, and only the male discourse can create Vivie's kind of "superwoman".

\section{LITERATURE REVIEW}

\section{A. Introduction to the Author}

Bernard Shaw (1856-1950) is one of the world famous playwrights, winner of Nobel Prize for literature in 1925. As a public speaker, Shaw gained the status of one of the most sought-after orators in England, and is world famous for its good humor and irony language master. Shaw was a freethinker, defender of women's rights, and advocate of equality of income. The life of Bernard Shaw is closely related to socialist movement. He had a careful reading of the Das Kapital, and openly stated that he is a socialist. The Norwegian playwright Henrik Ibsen had a great influence on Shaw's thinking. His range of subjects is very broad, of which there are many boutiques. During his long career, Shaw wrote over 50 plays. He continued to write them even in his 90s. Most of his works are known for their interesting and twisting plots, witty dialogues, and vivid characters. The author had always been opposed to literary works with the aim of "art for art's sake" and vulgar and boring fashion dramas, and advocated to write major social problems. Shaw held that art should serve social purposes by reflecting human life, revealing social contradictions and educating common people.

In his works, Shaw acutely mocked hypocrisy and $\sin$ in the capitalist society; ruthlessly disclosed the contradictions in its political, economic, cultural, social and other aspects and irrational social phenomenon, therefore his works can always win a good social repercussion. As to Shaw's works, they can be classified into the following four categories based on different features:

Firstly, his earlier plays were generally concentrated on social issues and headed for the repudiation of the contemporary economy, religion, society, morality and sins. Widower's House is an irrationally realistic and merciless disclosure of landlordism in the black inner cities where all lands were owned by the landlords. Mrs. Warren's Profession is a masterpiece about the economic oppression against female.

Secondly, Shaw did not write many plays on historical topics, through which he watched closely on the contemporary world. The significant and representative plays of this type contain Saint Joan published in 1923 and Caesar and Cleopatra in 1898.

Thirdly, Shaw created several other plays as well, expounding on the thoughts of "Life Force" which would produce brilliant merits that are equal with God and aim to settle every moral, metaphysical, and social issue in the world. The most representative one of this category is Man and Superman came out in 1904.

Fourthly, Shaw also wrote many plays upon various topics: for example, John Bull's Other Island describes racial issues; The Doctor's Dilemma narrates innocence, incapability, arrogance and stubbornness reflected in the medical community; Misalliance, Getting Married, and Fanny's First Day depicts the family and marital issues; Pygmalion is on art and culture; The Apple Cart makes a portrait of politics; Too True to Be Good is a really good work in Shaw's late stages, containing his nearly suspicion of misery about the themes of the ruthless and insaneness of the First World War and the young's wandering and disillusive sort of feelings towards life. Nowadays large number of Shaw's plays are always showed around the world, moreover, studies of his plays are frequently been put into effect.

\section{B. Introduction to the Novel}

This novel is a screenplay written by British dramatist Bernard Shaw from 1893 till 1894. Mrs. Warren has a 22-year-old daughter, Vivie, the top students of Women's College at Cambridge University, who is one of the few educated women in this community. She is honest, full of self-thought, and works in a law firm in London after graduation. Vivie made friends with Frank on her holiday. One day, Mrs. Warren with her two friends, the Reverend Samuel and Baron George Crofts come here, which makes Vivie feel like a fool by some force. In Vivie's view, George makes her very disgusted because he always puts on a pair of gentleman style, artificially speaking and acting. Mrs. Warren is very rich, but her daughter Vivie does not know her story. Vivie lived in school from primary school to university, and occasionally lived together with her maid who was taking care of her. She rarely met her mother, so she knows nothing about her mother's life. She does not know who her father is and what her mother is doing. Later, Vivie finds that her mother relied on a prostitute hall to accumulate wealth, so she is very dissatisfied with her mother, and angrily swearing her mother's degeneration. Mrs. Warren has to tell her daughter about her personal story, representing that she was forced to that behavior. Her mother's words make her believe that there are more profound reasons behind the surface area of career choice, so she expresses admiration for her mother. She thinks that her mother is a remarkably great woman and has an enterprising courage than anyone else.

The very next day in their house, Vivie is positively asking Praddy about her mother's history when Mrs. Warren and Jazz George Crofts come. Mrs. Warren, George, Reverend Samuel, and Frank chat together, talking about Vivie's marriage. Frank spots on Vivie's money and makes gallantly attempt to her. At the same time, Baron Crofts, five years older than Vivie, also asks her to be his wife. During his pleading, Crofts says that Mrs. Warren is still engaged in a brothel act, and he is one of the shareholders. Mrs. Warren desperately tries to defend for her, saying she had explained that before. Upon hearing, Vivie feels very angry, and she refuses to marry Crofts. For revenge, on his leaving occasion, 
Crofts reveals that Frank and Vivie are actually the son and the daughter of the same father; they are brother and sister, and previously Samuel priest and Mrs. Warren had an affair. In extreme pain, Vivie dashes out of the door and leaves her mother. And before leaving, she says she would struggle to live a righteous, moral life relying on her own efforts. She leaves the country cottage and returns to London. From that moment, Vivie never has any pity; she would not find a husband, nor does she need her mother; getting rid of all the entanglement, she put her entire body and mind into the work.

\section{NARRATIVE THEORY}

\section{A. General Introduction}

Narratology is a science of narration. Narration is defined as representations of a series of events whose relationships between time and causality are significant. Therefore, the narrative includes not only novels, but also films, dramas, comic books, news clips, diaries, chronicles and so on. Meanwhile, narrative can be constituted by a variety of symbolic medium, such as written or spoken language, visual image, posture and movement as well as combinations of these actions. Although the narrative is a kind of activity which had exited long after human appeared, narrative theory can be traced back to Aristotle's Poetics, but the emergence of the term narrative is only 30 years. In the year 1969 the French critic Tzvetan Todorov used the term narratologie in his Grammaire Du Decameron for the first time. Narratology is the study of narrative theory impacted by structuralism; it can be divided into classical and postclassical factions. Classical narratology aims to construct narrative grammar or poetics, meanwhile makes scientific research on components, structure relationships and operation laws of narrative works, and to explore the differences between works within the same structure framework. Post-classical narratology turned their attention to the structural characteristics and the interpretation to the readers about the law of interaction, to the discussion of the significance of specific narrative works, focusing on interdisciplinary research and the reciprocal actions of the author, the text, the reader and the social and historical context.

\section{B. Background and Three Research Types of Classical Narratology}

1. Background of Classical Narratology

Classical narratology is usually known as structuralism narratology. The West has a long history for the study of narrative structure, and Aristotle's Poetics is the earliest narrative work. Saussure's structural linguistics appearing in 1857 and lasting till 1913 changed the diachronic linguistic research into synchronic linguistic research; he believes that the focus should be the symbol system of language's internal structures rather than the history of these respective components in each their own process of evolution. Saussure laid the cornerstone for the theory of structuralism. In contrast with the traditional novel theory, structuralism narratologist will shift their attention away from the external text to the internal text, and strive to explore the internal structure rules and the relationship between the various elements in a narrative work. In the 1920s Russian formalism (which itself is subject to the influence of structural linguistics of Saussure) is also a source of narrative. An important ingredient of the narrative academic background is Anglo-American new criticism.

2. Three research types of Classical Narratology

Classical narratology can be divided into three types based on the object of studying.

The first category is narratologists directly affected by the Russian formalism scholars Propp. They focused on the narration of the story, tried hard to construct the story grammar, and to explore the function, structure rules, and even developing logics and so on in a story. Propp's book Folktale Morphology rated one of the most influential works of Russian literary in the 1920's, which is generally considered a book which opened a precedent in structuralism narratology. After Propp, narratologists in France and other countries made a systematic study of the deep and surface structural relations of a story, and constructed several story grammar patterns. Some of them focus on the relations between the static structures of the event, while others focus on the plot of the dynamic development process.

The second category which represents Genette as the typical representative concentrated on narrative discourse. In short, the narrative discourse is the way of storytelling. Kenan (2002) summarizes different narrative point of view from different narratologists in his book Narrative Fiction and he proposed that the story be independent from narrative discourse in three aspects: independent of the writers' styles as different styles can express the same story; independent of the language (English, French or Chinese); and independent of different medium or symbol systems (languages, movie images or dancing moves). In addition to the narrative point of view and speech forms, narratologists generally did not pay much attention to lexical features, syntactic features, writing (or voice) characteristics and the cohesion between sentences and other linguistic phenomena. This is probably because the narrative techniques are often not the selections of language (for example, to narrate event A first or event B first is not a matter of language choice), and narratologists usually just figuratively make use of linguistic model. In the study of discourse layer, narrative scientists focused on the expression mode and the structural relationship between objects and made systematic classification of various narrative techniques so as to construct a narrative grammar or narrative poetics.

The third type of studies, regarding Prince and Chatman (Chatman S.) as the representatives, holds that the story structure and discourse skills are both very important, so we should balance both during the research. Since the late 1970s narrative monograph generally belong to the third type. 


\section{Basic Characteristics of Post Classical Narratology}

Since the 1980s, attacking from both post structuralism and historicism, the research momentum of classical narrative was gradually declined (especially in the U.S.). Conforming to the readers' response and critic, cultural studies and other new emerging school, and paying attention to post classical narratology which takes the reader and context into account also came into being. Based on our research objective, we can divide postclassical narratology into two categories: one is to explore common characteristics (of different genres) in narrative works. Compared with classical narratology, this kind of postclassical narratology focuses on at least the following 5 different aspects of change. First, it turned from the work to the process of the readers' interpretation. Postclassical narratology is concerned with the readers' construction of the logic of the story and focuses on the exploration of the interaction between the reader and the text structure. Second, literary phenomenon swings from the compliance of the protocol ones to the deviated protocol ones, or from inside-literary narrative to outside-literary narrative. Third, in order to investigate the structure of the law, postclassical narratologists borrowed some new analysis tools from other fields. Fourth, from the narrative structure common to the diachronic narrative structure, we should pay attention to how social historical context influence or cause the development of narrative structure. Fifth, represented by feminism narratology, post classical narratology sway its concerns from the formal structure to relation of form structure and ideology. But this concern often needs a specific work to interpret it. (For some social and historical reasons, a writer in a work will choose a narrative form). Another kind of postclassical narratologists take the interpretation of specific meaning of the work as the main purpose, which is characterized by admitting the stability of narrative structure and the effectiveness of narrative conventions, and using the classical narrative patterns and concepts to analyze the works (sometimes revise and supplement in combination with the analysis). At the same time, while focusing on readers and social historical context, postclassical narratologists pay attention to interdisciplinary research, consciously absorb the theoretical concepts, critical perspectives and analysis models from other factions, so as to expand the scope of the study and overcome its limitations.

\section{A Detailed Analysis of Vivie from the Perspective of Narrative Theory}

\section{A. Narrative Voice Reflected in the Scene}

One of the special methods of studying narrative methods is to regard the script as a narrative text so as to explore the narrative voice outside the text because narrative voice is one of the most important parameters to measure the subjective and objective degrees of a narrative text. The deeper involvement the narrator, the stronger the narrative voice and the higher subjective narration are. Narratologist Chatman S. (1978) believes that public narration is always omniscient narrative voice of the author, which establishes the author's authority. In the script Mrs. Warren's Profession, in addition to the dialogues, objective descriptions of scenes can be considered as a public omniscient narrative perspective and the narrative voice stems from the scene describer. The scene layout in the first act of Mrs. Warren's Profession made an important cushion on Vivie's appearance.

“...A big canvas umbrella, stuck in the ground, keeps the sun off the hammock, in which a young lady is reading and making notes, her head towards the cottage and her feet towards the gate. In front of the hammock, and within reach of her hand, is a common kitchen chair, with a pile of serious-looking books and a supply of writing paper on it. "(Shaw, 2005, p.29)

In the British Society hundreds of years ago, riding a bike and reading and writing characteristics are strong social symbol of men, and they represent the independence, freedom and knowledge. When these symbols are attached to the female body, they will naturally form a strong contrast with the British social reality in which women were in a disadvantaged position, so the readers will focus more on these non-female symbols. These pre-narration symbols not only constitute the tone of Vivie's image, but also show the narrator's voice, and thus the narrator's authority has been established in the guidance of readers and viewers. Bal M. (2009) believes that the sender of the narrative voice is the narrator, not the author of the narration, and the narrator is "the actor who expresses the language symbol to compose of this paper" (p. 254). In dramatic narrative scenes introduction, the voice of the narrator and the author are in a high degree of unity. Once the dual authority of the narration acting on to the reader, it implants the reader a male symbol, intervenes readers for their previously experienced social female image at that time, thereby affects the readers' reading and thinking of the dramatic text.

\section{B. Involvement of Implied Author in Portrayal Description}

For Vivie's appearance, there is not any description in her first showing up, but the narrator deliberately made a detailed depiction on her clothes and temperament.

"She proffers her hand and takes his with a resolute and hearty grip. She is an attractive specimen of the sensible, able, highly-educated young middle-class Englishwoman. Age 22. Prompt, strong, confident, self-possessed. Plain business-like dress, but not dowdy. She wears a chatelaine at her belt, with a fountain pen and a paper knife among its pendants. "(Shaw, 2005, p.30)

In the story level, the narrative voice given by Vivie is stronger than other characters', but this statement has a default in the description of her dress and appearance and does not match very well with her strong narrative voice. The narrator does not describe Vivie's appearance, clothing color and texture, but only works heavy with her men kind of 
clothing. Compared with the later description of Mrs. Warren, there is a huge difference on Vivie's depiction at this point. For Mrs. Warren, when she first appears, the narrator not only introduces her hat and skirt, even mentions her "fashionable sleeves", the narrator has also done a detailed description of her figure, appearance, temperament and clothing for peer Crofts. This unbalanced descriptive method is clearly a deliberately unconventional narrative approach to tell Vivie's unique temperament, leaving a space for readers to define Vivie's image themselves. In this part in the level of narrative expression, the narrator intervenes in the narration relying on their own authority, resulting in some narrative blank about Vivie's image, and the result is to allow the reader to self- construct the missing gaps, which makes the great distance between Vivie and the readers. Wayne. C. B. (1991) stated, "the so-called 'implied author' is implicit in the works of the image of the author; it is not relied on the author's real existence or historical data, but based on the text; from reading perspective, the implied author is the author's image derived from the entire text by readers" (p. 71-77). In this section, the implied author holds on a critical attitude toward the new femininity; he or she not only seeks deliberately Vivie's masculine qualities but affirms the strong position of masculinity as well. Shen D. (2000) holds that if the implied author holds critical view on patriarchal ideology, then there would appear distance between the implied reader and Vivie. In this part of narration, there exists a great distance between the reader and Vivie. The missing gap image of Vivie makes it difficult for readers to accept, but they cannot construct it themselves. Therefore, the implied author is critical of Vivie's patriarchal position. The narrator's male discourse is established in the process of female discourse narration. Vivie's story expresses the struggle for independence of the new female's rebellious attitude towards patriarchy society. After large quantities of work, Weintraub (1977) thinks that Bernard Shaw himself also declared that women do not reasonably do the chores and women have the ability to undertake the important task of promoting the progress of mankind, and they should completely participate in social change in practice. The implied author's critical attitudes toward the narrator's male discourse confirm that the nature of the implied author in the text is the male. Hence, Vivie's image-shaping cannot jump out of the scope of patriarchal discourse and her words and deeds are not so much full of characteristics of "new women" but rather sketched out in accordance with an ideal male. Thus, in the male-dominated Vitoria times, a writer's description of women is very difficult to break through the limitations of the mainstream discourse mechanisms, but only to peel the spirits involved in a new woman under the framework of male and repeat the mistakes of Adam's rib transforming into Eve.

\section{Application of Feminism in Narratology}

The theory aims to introduce the feminist perspective into the narrative research, so that the latter has some degrees of change, or in other words, it can sexualize and contextualize narratology which purely analyzes characteristic forms. Although feminist narratology took a similar attitude to feminist criticism -- to change women's objectified and marginalized situation, its intention does not mean to contend and confront with male consciousness represented by narratology with feminist critique of ideology and does not firmly want to create a female narrative theory opposed to traditional narrative theory, because a female narrative theory criticizes and practices under the theoretical framework of classic narrative theory. On the contrary, the traditional narrative theory obtains human values in text meanings while sacrificing some accuracy and science. From Vivie's point of view, Mrs. Warren and Crofts represent not only powerful money which can direct people's lives, but also a reality principle behind it and the rules of a game. It requires great courage to resist this reality principle.

"Now once for all, mother, you want a daughter and Frank wants a wife. I dont want a mother; and I dont want a husband. I have spared neither Frank nor myself in sending him about his business. "(Shaw, 2005, p.95)

Vivie's declaration shows up her characteristics:

"But there are two subjects I want dropped, if you dont mind. One of them [to Frank] is love's young dream in any shape or form: the other [to Praed] is the romance and beauty of life, especially Ostend and the gaiety of Brussels. You are welcome to any illusions you may have left on these subjects: I have none. If we three are to remain friends, I must be treated as a woman of business, permanently single [to Frank] and permanently unromantic [to Praed]. "(Shaw, 2005, p.85)

Even today, this declaration also requires great courage, and is humbling. Vivie's characteristics of a clear occupation planning, unwillingness to show weakness to the man, smoking cigars in her pastime, and domineering to men endow Vivie with features of a new woman. She represents a "new women" image which is popular in London and Europe in the late nineteenth century. With the processing development of episode, her decision helps her finish the new women's inner transformation. Instead of being driven to distraction and rushing out the door, Vivie just turns toward the door as if she suddenly finds a new purpose in life after she hears that she is priest Samuel's illegitimate daughter-that is to say, she may be her lover Frank's half-sister. When Frank asks her where to go, she clearly replies: "At Honoria Fraser's chambers, 67 Chancery Lane, for the rest of my life" (Shaw, 1894, p.79). Shaw suggests here with a highly symbolic stage prompt: "She goes off quickly in the opposite direction to that taken by Crofts" (Shaw, 1894, p.79). She completely abandons the emotional things, turns herself into a realist, and cheers herself up to deal with reality, with the aim of taking up the cause. This new women, as Bernard Shaw has been launched in his dramatic creation of "unwomanly women", completes her metamorphosis thoroughly. He (Cheng, 1997: 28) states that while men have no hope, female are the carrier of "Life Force". She sacrifices her desires for the ideal, discards all her weaknesses of women, and arms herself with a strong will as well as an outstanding talent into the society. "Bernard Shaw once 
proposed, 'Women have the ability to bear the responsibility of promoting the progress of mankind; They should participate in the practice of social change'" (Weintraub, 1977, p.75). Although this play is named as Mrs. Warren's Profession, the focus is clearly on the character Vivie. Shaw indirectly condemns other people, including Mrs. Warren, but he devotes all his tenderness to Vivie, lest the insufficient motive and input. This kind of careful attention is a rarity of rarities in Bernard Shaw's "concept drama". Of course, the rationality and ruthless in Vivie's character shocks the male audience; it strikes me that most women also cannot completely agree with Mrs. Warren's attitude toward Vivie. In weighing the perfect female image and "Life Force", obviously Bernard Shaw shows more interest in the latter. To emphasize the work's intention to serve to reflect the reality of social problems, we weaken female appeals, and this method indeed plays a positive role in the development of feminism, changes people's views of the natural status of men and women, sweeps away stereotyped lady images at theater stages in Elizabeth era stage that a female should be delicate, gentle, and fair-skinned, accordingly provides a fresh template for the twentieth Century British literature to shape a female image and results in a far-reaching impact.

\section{Dualistic Construction in Subtext}

In the narrative structure of Mrs. Warren's Profession, the author brilliantly constructed several binary oppositions between characters, and showed varieties of contradictions in the play in this method. Among them, Vivie and Mrs. Warren's dualistic structure is the most contrasting one. Mrs. Warren is born poor and belongs to a working class. In order to rush to make a living, she and her sisters are almost the typical representatives of women of that period in the British Society. Mrs. Warren's success is entirely along the footsteps of the men down the way so that she opposes Vivie's combination with Frank and asks her daughter to marry with businessman Crofts who is thirty years older than Vivie due solely to his wealth. Although Vivie is highly educated, she lacks experience and is straightforward and robust, and consequently refuses to be controlled by others. In the story level, this kind of antagonistic relationship leads Vivie to a more independent, courageous, self-confident and rebellious spirit compared to British women of the same period.

There are three kinds of narrative perspectives after the age of Brecht: watch type, fixed type and split type. Split type is a kind of multi-perspective narration... several characters in the play separately act as a narrator in different periods of time... narrator's identity and attitude will directly affect the expression of the dramatic significance. The play takes exactly the third kind of narrative perspective. In the play, Mrs. Warren and her daughter's confrontation moves forward gradually along this split narrative structure. Mrs. Warren is a narrator for her own life and sense of values, while her daughter Vivien's view of the world is largely dependent on the play's action or expression design, and sometimes the omniscient narrator even expresses Vivien's ideas directly in the play instead of Vivien herself. On the surface level of Mrs. Warren's Profession, the essence of Bernard Shaw's expression is also his own society creation evolution, which challenges the traditional gender roles and temperament mode in a drama, and creates vital female with independent thinking and rational beauty. However, should we still define Vivien's kind of "independent" woman according to the male social standards? Or in other word, should men have the ability and discourse power to establish a vital female following their standards? The hidden text in the play tells the reader: the male is the world's leading power; women can only submit to it to survive, and "new women" self-speaking is ultimately meaningless, so it cannot be expressed by women themselves, therefore only the male discourse can create Vivie's kind of "superwoman". As a thinker and social reformer, in his dramas, Bernard Shaw emphasizes too much on works serving to the ideology, but this weakens the character's artistic appeal, causing intellectual and emotional imbalance in his female image and contributing to the hidden text's indication of his standpoint, that is the androcentrism, when he tried to show his intention to focus on woman's social rights and interests.

\section{CONCLUSION}

This paper analyzed Vivie's image in Mrs. Warren's Profession through approaches of narrative theory. By using narrative voice reflected in the scene, involvement of implied author in portrayal description and application of feminism in narratology, it shows that due to social relations, Vivie cannot get rid of low social status of women's fatalism even though she always dresses and acts like a man to manifest her new woman image. Vivie, as a top student of women's college at Cambridge University, is one of the few highly educated women in female community; she is also a typical representative of "new woman image" in the capitalist society. She is honest, full of great integrity and self-reliance, and dares to fight against decadent forces and asked for the liberation of personality.

The paper made a sharp contrast between Vivie and her mother Mrs. Warren by applying dualistic construction in subtext. However, at the time of capitalist society, men are in the world's leading position, so the image of both Vivie and Mrs. Warren could not get out of patriarchal discourse areas, and only under a larger male framework can it be possible to "peel" a "new woman image". This play showed the condemnation and criticism of traditional moral values and false ethical standards, as well as his concerns about real life and revelations of social misfortune. The social root of women's tragic fate lies in the exploitative nature of the capitalist production mode.

\section{REFERENCES}

[1] Bal, M. (2009). Narratology: Introduction to the Theory of Narrative ( $3^{\text {rd }}$ ed.). Canada: University of Toronto Press.

[2] Chatman, S. (1978). Story and Discourse, Narrative Structure in Fiction and Film. New York: Cornell University Press. 
[3] Genette, G. (1983). Narrative Discourse: An Essay in Method. New York: Cornell University Press.

[4] Harris, F. (2006). Bernard Shaw (J.D., Huang). Bei Jing: Unity Press. (Originial work published in 1931).

[5] He, Z. C. (1997). Bernard Shaw: The Pioneer of Western Feminist Movement. Journal of PLA University of Foreign languages, 2, 28-30.

[6] Kenan, S. R. (2002). Narrative Fiction ( $2^{\text {nd }}$ ed.). London and New York: Routledge,.

[7] Propp, V. (1968). Morphology of the Folktale. Austin: University of Texas Press

[8] Shaw, G. B. (2005). Mrs. Warren's Profession. Bei Jing: The School Audio-visual Publishing House.

[9] Shen, D. (2000). Does 'Implied Author' Necessary?---The Divergence in Narrative World and Online Conversations. Foreign Literatures, 3, 7-13.

[10] Shen, D. (2005). The Research on Narrative Theory of British and American Novels. Bei Jing: Peking University Press.

[11] Stanzel, F. K. (1986). A Theory of Narrative. Cambridge: Cambridge University Press.

[12] Tan, J. Q. (2008). An Introduction of Narratology: From Classic Narratology to Post-classic Narratology. Bei Jing: Higher Education Press.

[13] Wayne, C. B. (1991). The Rhetoric of Fiction ( $2^{\text {nd }}$ ed.). London: Penguin Books.

[14] Weintraub, R. (1977). Fabian Feminist: Bernard Shaw and Woman. Pennsylvania: Pennsylvania State University Press.

Lin Bai was born in Lvliang, China in 1991. She is a postgraduate student in the School of Foreign Languages at Shanxi Normal University in China. She received her B.A. degree in English from Modern College of Science and Arts, Shanxi Normal University in 2014.

Jie Qin was born in Gaoping, China in 1975. He received his Ph.D. degree from Shanghai Normal University. He is currently associate professor and master's supervisor in Shanxi Normal University. His research interests include theories and practices in English course and language teaching and psycholinguistics. Doctor Qin has took part in a series of research and teaching activities during which he published several articles; he was also responsible for at least 9 scientific research project. 